\title{
Determinan Faktor Yang Berhubungan Dengan Kejadian Berat Badan Lahir Rendah (BBLR) Di Rumah Sakit Umum Daerah Zainoel Abidin Banda Aceh
}

\section{Determinants of Factors Associated with the Incidence of Low Birth Weight (LBW) at the Zainoel Abidin Regional General Hospital Banda Aceh}

\author{
Ulfa Husna Dhirah ${ }^{1}$, Dian Ulviara ${ }^{2}$, Eva Rosdiana ${ }^{3}$, Marniati $^{4}$ \\ Universitas Ubudiyah Indonesia, Jln. Alue Naga Desa Tibang, Kecamatan Syiah Kuala, Banda Aceh, \\ Indonesia \\ *Correspoding Author : ulfahusna@uui.ac.id
}

\begin{abstract}
Abstrak
Kejadian BBLR jika tidak ditangani maka dapat menimbulkan permasalahan pada sistem organ tubuh seperti gangguan pernafasan, sistem pencernaan, dan persyarafan. Data dari Dinas Kesehatan Provinsi Aceh bayi BBLR sebanyak 1,5\% dari 100.265 kelahiran hidup dan di tahun 2016 kasus BBLR sebanyak 2\% dari 116.816 kelahiran hidup. Untuk mengetahui faktor usia, paritas, komplikasi kehamilan dan hamil kembar yang berhubungan dengan kejadian BBLR. Penelitian ini bersifat analitik dengan pendekatan case control. Teknik pengambilan sampel dilakukan secara random sampling, dengan perbandingan 1:1 yaitu kelompok kasus ibu bersalin yang mengalami BBLR dan kelompok kontrol ibu bersalin normal sebanyak 42 orang. Analisa data dilakukan dengan menggunakan uji statistik chi-square dengan batas kemaknaan 95\% $(\mathrm{P}<0,05)$ dan nilai OR. Analisa univariat didapatkan yaitu umur berisiko 22 responden $(52,4 \%)$, paritas primipara/multipara 29 responden $(69,0 \%)$, tidak ada komplikasi kehamilan 24 responden $(57,1 \%)$, dan tidak ada hamil kembar 33 responden $(78,6 \%)$. Analisa bivariat yaitu ada hubungan umur ( $\mathrm{P}$-value $=0,031$, OR=5,000, paritas ( $\mathrm{P}$ value $=0,026, \mathrm{OR}=5,667)$, komplikasi kehamilan $(\mathrm{P}$-value $=0,029, \mathrm{OR}=4,200)$, dan hamil kembar (P-value=0,044, OR =2,400) dengan kejadian BBLR. Ada hubungan umur, paritas dan komplikasi kehamilan dengan kejadian BBLR, tidak ada hubungan hamil kembar dengan kejadian BBLR. Diharapkan agar tenaga kesehatan dapat memberikan penyuluhan kesehatan pada calon ibu dan ibu hamil agar mempersiapkan fisik, mental maupun psikologis saat hamil dan bersalin agar nantinya dapat melahirkan anak yg sehat dan normal seperti yang diharapkan semua orang.
\end{abstract}

Kata kunci : BBLR, Umur, Paritas, Komplikasi Kehamilan, Hamil Kembar 


\begin{abstract}
LBW if not handled, it can cause problems in the body's organ systems such as respiratory disorders, digestive system, and nerves. Data from the Aceh Provincial Health Office of LBW babies were $1.5 \%$ of 100,265 live births and in 2016 cases of LBW were $2 \%$ of 116,816 live births. To determine the factors of age, parity, pregnancy complications and multiple pregnancies associated with LBW incidence. This research is analytic with a case control approach. The sampling technique was carried out by random sampling, with a ratio of 1: 1 , namely the case group of women who gave birth who experienced LBW and the control group of women who gave birth normally as many as 42 people. Data analysis was performed using the chi-square statistical test with a significance limit of $95 \%(\mathrm{P}<0.05)$ and an OR value. Univariate analysis found that the age at risk of 22 respondents $(52.4 \%)$, parity of primiparous / multiparous 29 respondents (69.0\%), 24 respondents $(57.1 \%)$ had no pregnancy complications, and 33 respondents $(78), 6 \%)$. Bivariate analysis, namely there was a relationship between age $(\mathrm{P}$-value $=0.031, \mathrm{OR}=5,000$, parity $(\mathrm{P}$-value $=0.026, \mathrm{OR}=5.667)$, pregnancy complications $(\mathrm{P}$-value $=0.029, \mathrm{OR}=4.200)$, and multiple pregnancy $(\mathrm{P}$ - value $=$ $0.044, \mathrm{OR}=2,400$ ) with the incidence of $\mathrm{LBW}$.There is a relationship between age, parity and pregnancy complications with the incidence of LBW, there is no relationship between multiple pregnancies and the incidence of LBW.It is hoped that health workers can provide health education to prospective mothers and pregnant women to prepare physically, mentally and psychologically during pregnancy and childbirth so that later you can give birth to a healthy and normal child as expected by everyone.
\end{abstract}

Keywords: LBW, Age, Parity, Pregnancy Complications, Twin Pregnancy

\title{
PENDAHULUAN
}

Bayi berat lahir rendah (BBLR) merupakan bayi baru lahir dengan berat badan lahirnya pada saat kelahiran kurang dari 2500 gram. BBLR jika tidak ditangani dengan cepat maka bisa menimbulkan permasalahan pada sistem organ tubuh seperti gangguan pernafaasan, gangguan sistem pencernaan serta gangguan persyarafan. Dahulu bayi baru lahir dengan berat badan lahir kurang dari 2500 gram disebut prematur (Mayanti, et al, 2011).

Berdasarkan hasil pengumpulan data indikator kesehatan provinsi yang berasal dari fasilitas pelayanan kesehatan, proporsi BBLR berkisar antara 0,91\% 
Journal of Healthcare Technology and Medicine Vol. 6 No. 2 Oktober 2020

Universitas Ubudiyah Indonesia

e-ISSN : 2615-109X

(Gorontalo) dan 18,89\% (Jawa Tengah), pada tahun 2016 berkisar antara 6,90\% (Sumatra Utara). Angka tersebut belum mencerminkan kondisi sebenarnya yang ada di masyarakat karena belum semua berat badan bayi yang dilahirkan dapat dipantau oleh petugas kesehatan, khususnya yang ditolong oleh dukun atau tenaga non kesehatan lainnya (Profil Kesehatan RI, 2017).

Berdasarkan data yang diperoleh dari Profil Kesehatan Provinsi Aceh tahun 2017, Angka Kematian Bayi (AKB) tiga tahun terakhir cenderung mengalami peningkatan, dimana diketahui bahwa jumlah kematian bayi di Aceh pada tahun 2015 sebanyak 646 orang, tahun 2016 meningkat menjadi 807 dan pada tahun 2017 meningkat kembali menjadi 943 orang. sedangkan angka kejadian BBLR yaitu sebesar 21\% (Profil Kesehatan Indonesia, 2017).

Data dari Dinas Kesehatan Kota Banda Aceh tahun 2017, diketahui bahwa bayi BBLR di Provinsi Aceh sebanyak 1,5\% dari 100.265 kelahiran hidup dan di tahun 2016 kasus BBLR sebanyak 2\% dari 116.816 kelahiran hidup. Penyebab kematian bayi diantaranya disebabkan karena asfiksia dan BBLR. Hasil pemantauan selama kurun waktu 2017 , ada 15 bayi dengan kasus BBLR di Kota Banda Aceh dengan BBLR tertinggi di UPTD Baiturrahman 6 bayi (Dinas Kesehatan Banda Aceh, 2017).

Hasil studi pendahuluan yang diperoleh di RSUDZA Banda Aceh Tahun 2018 didapatkan data dari Tahun 2017 jumlah bayi dengan BBLR sebanyak 135 (14\% ) dari 947 kelahiran sedangkan data tahun 2018 jumlah bayi lahir dengan BBLR sebanyak 151 (17\%) dari 978 kelahiran hidup. Data tersebut menunjukkan bahwa terjadi peningkatan kejadian BBLR pada tahun 2018.

\section{METODE PENELITIAN}

Penelitian ini bersifat analitik dengan pendekatan case control yang digunakan untuk menentukan hubungan antara variabel bebas dan variabel terikat. Populasi dalam penelitian ini ada populasi kasus seluruh bayi yang lahir dengan berat badan <2500 sebanyak 151 orang dan populasi kontrol seluruh bayi yang lahir dengan berat badan diatas 2500 gram sebanyak 978 orang. Teknik pengambilan sampel dalam penelitian ini menggunakan desain stratified random sampling. 
Journal of Healthcare Technology and Medicine Vol. 6 No. 2 Oktober 2020

Universitas Ubudiyah Indonesia

e-ISSN : 2615-109X

Instrumen pengumpulan data yaitu alat bantu berupa Checklist. Penelitian ini telah dilaksanakan pada tanggal 4-30 Maret 2019 di Rumah Sakit Umum Daerah Zainoel Abidin Banda Aceh. Pengolahan data yang digunakan pada penelitian ini adalah dengan cara data yang telah dikumpulkan diolah dengan cara komputerisasi menggunakan program SPSS. Analisis data dalam penelitian ini yaitu analisis univariate, dan bivariate.

\section{HASIL PENELITIAN}

1. Analisa Univariat

a. Variabel Independen

Tabel 4.1

Distribusi Frekuensi Variabel Independen di Rumah Sakit Umum Daerah Zainoel Abidin Banda Aceh

\begin{tabular}{llcccc}
\hline No & \multicolumn{1}{c}{ Variabel Independen } & \multicolumn{2}{c}{ Kasus } & \multicolumn{2}{c}{ Kontrol } \\
\hline & U & \% & n & $\%$ \\
1 & Umur & & & & \\
& 1. Berisiko (<20->35 tahun) & 15 & 68,2 & 7 & 31,8 \\
& 2. Tidak berisiko (20-35 tahun) & 6 & 30,0 & 14 & 70,0 \\
\hline 2 & Paritas & 12 & 41,4 & 17 & 58,6 \\
& 1. <3 Anak & 9 & 69,2 & 4 & 30,8 \\
\hline 2. $\geq 3$ Anak & & & & \\
\hline 3 & Komplikasi Kehamilan & 13 & 72,2 & 5 & 27,8 \\
& 1. Ada & 8 & 33,3 & 16 & 66,7 \\
\hline 2. Tidak ada & & & & \\
& Hamil Kembar & 6 & 66,7 & 3 & 33,3 \\
& 1. Ya & 15 & 45,5 & 18 & 54,5 \\
\hline
\end{tabular}

2. Analisa Bivariat

a. Hubungan Umur dengan Kejadian BBLR

Tabel 4.2

Hubungan Umur dengan Kejadian BBLR di Rumah Sakit Umum Daerah Zainoel Abidin Banda Aceh

\begin{tabular}{lcccccc}
\hline \multirow{2}{*}{ Umur } & \multicolumn{4}{c}{ BBLR } & \multirow{2}{*}{ P- } & OR \\
\cline { 2 - 5 } & \multicolumn{2}{c}{ Kasus } & \multicolumn{2}{c}{ Kontrol } & Palue & \\
\cline { 2 - 5 } & $\mathrm{n}$ & $\%$ & $\mathrm{n}$ & $\%$ & Valu \\
\hline Berisiko (<20 dan >35 tahun) & 15 & 71,4 & 7 & 33,3 & & \\
Tidak Berisiko (20-35 tahun) & 6 & 28,6 & 14 & 66,7 & 0,031 & 5,000 \\
Total & $\mathbf{2 1}$ & $\mathbf{1 0 0}$ & $\mathbf{2 1}$ & $\mathbf{1 0 0}$ & & \\
\hline
\end{tabular}


Journal of Healthcare Technology and Medicine Vol. 6 No. 2 Oktober 2020

Universitas Ubudiyah Indonesia

e-ISSN : 2615-109X

b. Hubungan Paritas dengan Kejadian BBLR

Tabel 4.3

Hubungan Paritas dengan Kejadian BBLR di Rumah Sakit Umum Daerah Zainoel Abidin Banda Aceh

\begin{tabular}{|c|c|c|c|c|c|c|}
\hline \multirow{3}{*}{ Paritas } & \multicolumn{4}{|c|}{ BBLR } & \multirow{3}{*}{$P$ Value } & \multirow{3}{*}{ OR } \\
\hline & \multicolumn{2}{|c|}{ Kasus } & \multicolumn{2}{|c|}{ Kontrol } & & \\
\hline & $\mathrm{n}$ & $\%$ & $\mathrm{n}$ & $\%$ & & \\
\hline$\geq 3$ Anak & 9 & 42,9 & 17 & 81,0 & & \\
\hline$<3$ Anak & 12 & 57,1 & 4 & 19,0 & 0,026 & 5,667 \\
\hline Total & 21 & 100 & 21 & 100 & & \\
\hline
\end{tabular}

c. Hubungan Komplikasi Kehamilan dengan Kejadian BBLR

Tabel 4.4

Hubungan Komplikasi Kehamilan dengan Kejadian BBLR di Rumah Sakit Umum Daerah Zainoel Abidin Banda Aceh

\begin{tabular}{|c|c|c|c|c|c|c|}
\hline \multirow{3}{*}{$\begin{array}{l}\text { Komplikasi } \\
\text { Kehamilan }\end{array}$} & \multicolumn{4}{|c|}{ BBLR } & \multirow{3}{*}{ P-Value } & \multirow{3}{*}{ OR } \\
\hline & \multicolumn{2}{|c|}{ Kasus } & \multicolumn{2}{|c|}{ Kontrol } & & \\
\hline & $\mathrm{n}$ & $\%$ & $\mathrm{n}$ & $\%$ & & \\
\hline Ada & 13 & 61,9 & 5 & 23,8 & & \\
\hline Tidak Ada & 8 & 38,1 & 16 & 76,2 & 0,029 & 4,200 \\
\hline Total & 21 & 100 & 21 & 100 & & \\
\hline
\end{tabular}

d. Hubungan Hamil Kembar dengan Kejadian BBLR

Tabel 4.5

Hubungan Hamil Kembar dengan Kejadian BBLR di Rumah Sakit Umum Daerah Zainoel Abidin Banda Aceh

\begin{tabular}{|c|c|c|c|c|c|c|}
\hline \multirow{3}{*}{ Hamil Kembar } & \multicolumn{4}{|c|}{ BBLR } & \multirow[b]{3}{*}{ P-Value } & \multirow[b]{3}{*}{ OR } \\
\hline & \multicolumn{2}{|c|}{ Kasus } & \multicolumn{2}{|c|}{ Kontrol } & & \\
\hline & $\mathrm{n}$ & $\%$ & $\mathrm{n}$ & $\%$ & & \\
\hline $\mathrm{Ya}$ & 6 & 28,6 & 3 & 14,3 & \multirow{3}{*}{0,044} & \multirow{3}{*}{2,400} \\
\hline Tidak & 15 & 71,4 & 18 & 85,7 & & \\
\hline Total & 21 & 100 & 21 & 100 & & \\
\hline
\end{tabular}

\section{PEMBAHASAN}

\section{Hubungan Umur dengan Kejadian BBLR}

Berdasarkan hasil penelitian dapat dilihat bahwa dari kelompok kasus pada umur berisiko ( $<20$ tahun dan $>35$ tahun) yaitu $71,4 \%$, sedangkan kelompok kontrol yaitu 33,3\%. Hasil uji statistik didapatkan P-value=0,031 dan nilai $\mathrm{OR}=5,000$, yang artinya ada hubungan faktor umur dengan kejadian BBLR, dimana usia ibu bersalin berisiko ( $<20$ tahun dan $>35$ tahun) mempunyai 
Journal of Healthcare Technology and Medicine Vol. 6 No. 2 Oktober 2020

Universitas Ubudiyah Indonesia

e-ISSN : 2615-109X

peluang 5 kali lebih besar untuk melahirkan bayi BBLR dibandingkan dengan usia yang tidak berisiko (20-35 tahun).

Hasil penelitian ini sesuai dengan penelitian yang dilakukan oleh Dian Alya 2013 di RSIA Banda Aceh, penelitian ini menggunakan pendekatan case control dan sampel diambil secara purposive sampling. Hasil penelitian menunjukkan bahwa dari 37 ibu dengan kategori umur beresiko ada 29 ibu $(24,6 \%)$ yang melahirkan bayi dengan BBLR. Sedangkan dari 81 ibu dengan kategori umur tidak beresiko hanya 30 ibu $(25,4 \%)$ yang melahirkan bayi dengan BBLR. Hasil analisa perbedaan proporsi terpapar faktor resiko antara kelompok kasus dengan kelompok kontrol secara statistik dengan nilai $\mathrm{P}=0,000$ $(\mathrm{P}<0,05)$ dan nilai OR 6,163.

Sejalan dengan teori Trihardiani (2011), kehamilan yang terjadi pada usia $<20$ tahun atau $>35$ tahun memiliki kecenderungan tidak terpenuhinya kebutuhan gizi yang adekuat untuk pertumbuhan janin yang akan berdampak terhadap bayi dengan berat badan lahir rendah. Usia ibu $<20$ tahun pada saat hamil berisiko terjadinya BBLR 1,5-2 kali lebih besar dibandingkan ibu hamil yang berusia 20-35 tahun. Usia ibu saat hamil mempengaruhi kondisi kehamilan ibu karena selain hubungan dengan kematangan organ reproduksi juga berhubungan dengan kondisi psikologis terutama kesiapan dalam menerima kehamilan.

Menurut peneliti responden yang berada pada umur berisiko yaitu 1840 tahun berpeluang mengalami BBLR. Apabila hamil pada usia dibawah 20 tahun alat reproduksi belum siap dan pada saat kehamilan berlangsung akan terjadi masalah seperti melahirkan bayi yang BBLR. Sedangkan responden pada umur 35 tahun ke atas akan banyak mengalami masalah dalam persalinan karena perubahan pada jaringan-jaringan kandungan dan juga jalan lahir tidak lentur lagi, selain itu alat reproduksi sudah tidak mampu bereproduksi dengan baik sehingga rentan terjadi BBLR.

Hasil penelitian juga menunjukkan pada umur yang berisiko yaitu $<20$ tahun dan >35 tahu dapat melahirkan bayi yang normal. Hal ini disebabkan karena responden yang rutin memeriksakan kehamilannya juga ditunjang 
Journal of Healthcare Technology and Medicine Vol. 6 No. 2 Oktober 2020

Universitas Ubudiyah Indonesia

e-ISSN : 2615-109X

dengan ekonomi yang memadai sehingga dapat mengkonsumsi makanan yang sehat dan bergizi selama kehamilan dan melahirkan bayi dengan berat badan yang normal.

\section{Hubungan Paritas dengan Kejadian BBLR}

Berdasarkan hasil penelitian dapat dilihat bahwa dari kelompok kasus pada paritas $\geq 3$ anak yaitu $42,9 \%$, sedangkan kelompok kontrol pada yaitu 81,0\%. Hasil uji statistik didapatkan $\mathrm{P}$-value $=0,026$ dan nilai $\mathrm{OR}=5,667$, yang artinya ada hubungan faktor paritas dengan kejadian BBLR dimana ibu dengan paritas lebih dari 3 anak mempunyai peluang 5 kali lebih besar melahirkan bayi BBLR dibandingkan dengan paritas yang kurang dari 3 anak.

Hasil penelitian ini sesuai dengan penelitian yang dilakukan oleh Riska Fajri (2015), penelitian ini menggunakan desain case control. Hasil penelitian menunjukkan bahwa dari 26 responden yang paritas primipara dengan kejadian berat badan lahir rendah sebanyak 22,2\%. Sedangkan dari 46 responden yang paritas multipara dan mengalami kejadian berat badan lahir rendah sebanyak $77,8 \%$. Hasil statistik diperoleh $\mathrm{p}$ value $=0,027$, artinya ada hubungan paritas dengan kejadian BBLR Di RSUD Zainoel Abidin Banda Aceh Tahun 2015 dengan nilai $\mathrm{OR}=3,500$ yaitu ibu yang paritas multipara mempunyai peluang 3 kali lebih besar berat badan lahir dibandingkan dengan ibu paritas primipara.

Sejalan dengan teori yang dikemukakan oleh Sudarti (2012), ibu dengan paritas 1 dan> 4 beresiko melahirkan BBLR, pada primipara belum siapnya fungsi organ dalam menjaga kehamilan dan menerima kehadiran janin,sedangkan ibu yang pernah melahirkan anak 4 kali atau lebih akan mengakibatkan terganggunya uterus terutama pada pembuluh darah dan kerusakannya dinding pembuluh darah pada uterus sehingga dapat mempengaruhi nutrisi pada janin sehingga dapat terjadinya gangguan pada pertumbuhan janin sehingga melahirkan bayi dengan BBLR.

Menurut peneliti persalinan yang berulang-ulang akan mempunyai banyak risiko terhadap kehamilan persalinan, semakin banyak anak yang dilahirkan, maka semakin berisiko untuk mengalami kejadian BBLR disebabkan rahim yang meregang karena terlalu banyak melahirkan anak. Telah 
Journal of Healthcare Technology and Medicine Vol. 6 No. 2 Oktober 2020

Universitas Ubudiyah Indonesia

e-ISSN : 2615-109X

terbukti bahwa dari hasil penelitian di RSUDZA Banda Aceh terlihat persalinan kedua dan ketiga adalah persalinan yang paling aman karena rahim masih dalam keadaan baik dan tidak meregang. Kemudian hasil penelitian menunjukkan bahwa paritas $\geq 3$ anak juga dapat melahirkan bayi yang normal karena selama kehamilan bayi mendapatkan asupan makanan yang cukup dan dipengaruhi juga oleh faktor pekerjaan ibu sebagai IRT sehingga ibu banyak beristirahat selama kehamilan sampai melahirkan bayi dengan berat badan yang normal.

\section{Hubungan Komplikasi Kehamilan dengan Kejadian BBLR}

Berdasarkan hasil penelitian dapat dilihat bahwa dari kelompok kasus yang ada komplikasi kehamilan yaitu 61,9\%, sedangkan dari kelompok kontrol yang ada komplikasi yaitu 23,8\%. Hasil uji statistik didapatkan P-value=0,029 dan nilai $\mathrm{OR}=4,200$, yang artinya ada hubungan faktor komplikasi kehamilan dengan kejadian BBLR dimana komplikasi kehamilan yang dialami ibu bersalin mempunyai peluang 4 kali lebih besar melahirkan bayi BBLR dibandingkan dengan yang tidak ada komplikasi selama kehamilan.

Hasil penelitian ini sesuai dengan penelitian yang dilakukan oleh Feni Sasmita (2014), penelitian ini menggunakan desain cross sectional dengan teknik pengambilan sampel menggunakan teknik random sampling. di RSUD Zainoel Abidin Banda Aceh, hasil analisa statistik menunjukkan hubungan tersebut bermakna dengan nilai $\alpha=0,05$ dan $p$ value $=0,03$. Hal tersebut berarti hipotesis penelitian menyatakan bahwa ada hubungan komplikasi selama masa kehamilan dengan kejadian BBLR.

Hasil penelitian ini sejalan dengan teori yang dikemukakan oleh Jannah (2012) komplikasi adalah penyakit yang baru timbul kemudian sebagai tambahan penyakit yang sudah ada. Ada beberapa komplikasi pada ibu dan janin selama kehamilan. ibu yang mengalami komplikasi kehamilan mempunyai risiko 2,3 kali untuk mempunyai bayi dengan BBLR dibandingkan dengan ibu yang tidak mengalami komplikasi kehamilan.

Menurut peneliti terdapat hubungan antara komplikasi kehamilan dengan kejadian BBLR. Komplikasi kehamilan yang dialami responden di ruang bersalin RSUZA Banda Aceh seperti perdarahan, preeklampsi/eklampsi 
Journal of Healthcare Technology and Medicine Vol. 6 No. 2 Oktober 2020

Universitas Ubudiyah Indonesia

e-ISSN : 2615-109X

atau kejadian ketuban pecah dini, anemia dapat meningkatkan terjadinya BBLR. Ibu yang mengalami perdarahan disebabkan karena plasenta previa atau solusio plasenta sehingga besar kemungkinan melahirkan bayi BBLR. Pada ibu yang mengalami KPD jika disertai kontraksi dan infeksi maka bayi akan lahir sebelum waktunya (BBLR). Komplikasi kehamilan yang dialami ibu dapat juga dipengaruhi karena faktor asumsi makanan dan pekerjaan. Ibu yang hamil tanpa ada komplikasi dapat melahirkan bayi yang sehat dan normal, Selain itu bayi lahir dengan BBLR juga dapat dialami oleh ibu yang tidak mengalami komplikasi selama kehamilan, seperti bu yang mengalami KPD dapat disebabkan karena faktor pekerjaan yang berat sehingga menimbulkan kontraksi dan bayi lahir sebelum waktunya.

\section{Hubungan Hamil Kembar dengan Kejadian BBLR}

Berdasarkan hasil penelitian dapat dilihat bahwa dari kelompok kontrol yang ada hamil kembar yaitu 28,6\%, sedangkan dari kelompok kasus yang ada hamil kembar yaitu 14,3\%. Hasil uji statistik didapatkan P-value=0,044 dan nilai $\mathrm{OR}=2,400$, yang artinya ada hubungan faktor kehamilan ganda dengan kejadian BBLR, dimana ibu dengan hamil kembar mempunyai peluang 2 kali lebih besar melahirkan bayi BBLR dibandingkan dengan ibu yang tidak hamil kembar.

Hasil penelitian ini sesuai dengan penelitian yang dilakukan oleh Dian Alya di RSIA Banda Aceh tahun 2013, penelitian ini menggunakan pendekatan case control dan sampel diambil secara purposive sampling. Hasil penelitian didapatkan hasil dari 118 ibu bersalin $91(77,1 \%)$ ibu melahirkan bayi tidak gemeli, dan 27 (22,9\%) ibu melahirkan bayi gemeli.

Hasil uji statistik ada hubungan antara kehamilan kembar dengan bayi berat lahir rendah (BBLR) dengan nilai $\mathrm{P}=0,016$ dan nilai $\mathrm{OR} 3,028$. Hasil penelitian ini sejalan dengan teori yang dikemukakan oleh Susilowati (2016), menyatakan bahwa pada kehamilan ganda berat masing-masing anak lebih kecil dari rata-rata, berat totalnya lebih besar dari bayi tunggal. Salah satu anak dapat lebih berat 50 sampai 1000 gram dari lainnya. Setengah kasus anaknya mempunyai berat badan cukup bulan, seperdelapan kehamilan kedua bayinya 
Journal of Healthcare Technology and Medicine Vol. 6 No. 2 Oktober 2020

Universitas Ubudiyah Indonesia

e-ISSN : 2615-109X

dibawah 1800 gram. Tiga perdelapan sisanya antara 1500 sampai 2500 gram. Sedangkan Kurtz menjelaskan bahwa tidak ada satupun kembar tiga yang berat totalnya mencapai 7500 gram, berarti berat rat-rata masing-masing anak kurang dari 2500 gram. Anak edua dan ketiga mortalitasnya lebih besar dari pada anak pertama.

Menurut peneliti menunjukkan ada hubungan hamil kembar dengan BBLR, karena BBLR bisa saja dialami oleh ibu hamil dengan janin tunggal. Tetapi, risiko terjadi BBLR lebih besar dialami oleh ibu yang hamil kembar, karena nutrisi yang banyak diperlukan jika ibu sedang hamil kembar karena pasokan darah untuk kehamilan ganda terbagi dua atau lebih untuk masingmasing janin. Akan tetapi, hasil penelitian juga menunjukkan bahwa ibu yang ada hamil kembar dapat melahirkan bayi dengan berat badan yang normal. Hal ini disebabkan karena asupan makanan bergizi yang dikonsumsi ibu tercukupi untuk memenuhi kebutuhan nutrisi bayi kembar selama dalam kandungan. Sangat dianjurkan terutama untuk ibu dengan kehamilan ganda agar lebih meningkatkan asupan nutrisi pada saat kehamilan guna mencegah terjadinya BBLR pada bayi yang akan dilahirkan. Ibu yang hamil janin tunggal dapat memenuhi nutrisi untuk bayinya karena tidak terbagi dua sehingga pasokan aliran darah untuk bayi tercukupi.

\section{SIMPULAN}

Berdasarkan hasil penelitian ada hubungan umur dengan kejadian BBLR dengan nilai $\mathrm{P}$-value $=0,031(\mathrm{P} \leq 0,05)$ dan nilai $\mathrm{OR}=5,000$, ada hubungan paritas dengan kejadian BBLR dengan nilai $\mathrm{P}$-value $=0,026(\mathrm{P} \leq 0,05)$ dan nilai $\mathrm{OR}=5,667$. ada hubungan komplikasi kehamilan dengan kejadian BBLR dengan nilai Pvalue $=0,029(\mathrm{P} \leq 0,05)$ dan nilai $\mathrm{OR}=4,200$, ada hubungan hamil kembar dengan kejadian BBLR dengan nilai $\mathrm{P}$-value $=0,044(\mathrm{P}>0,05)$ dan nilai $\mathrm{OR}=2,400$.

\section{SARAN}

Diharapkan penelitian ini menjadi bahan masukan bagi tenaga kesehatan dapat memberikan penyuluhan kesehatan pada calon ibu dan ibu hamil agar 
Journal of Healthcare Technology and Medicine Vol. 6 No. 2 Oktober 2020

Universitas Ubudiyah Indonesia

e-ISSN : 2615-109X

mempersiapkan fisik, mental maupun psikologis saat hamil dan bersalin agar nantinya dapat melahirkan anak yg sehat dan normal seperti yang diharapkan semua orang.

\section{UCAPAN TERIMA KASIH}

Ucapan terima kasih kepada Universitas Ubudiyah Indonesia yang telah memberikan dukungan finansial dalam penelitian ini dan ucapan terima kasih kepada Direktur RSUDZA Banda Aceh yang telah memberikan izin penelitian diwilayah kerjanya dan para responden yang telah membantu peneliti dalam memberikan informasi yang dibutuhkan peneliti.

\section{DAFTAR PUSTAKA}

Alya, Dian. 2013. Faktor-faktor yang Berhubungan dengan Bayi Berat Lahir Rendah Di Rumah sakit Ibu dan Anak Banda Aceh Tahun 2013 (Diunduh 2 November 2018)

Asiyah. 2010. Kakateristik bayi berat lahir rendah (BBLR) sampai triwulan II tahun 2009 di kota kediri (Diunduh 5 November 2018)

Deslidel, Hj, dkk. . 2012 .Asuhan Neonatus, Bayi dan Balita. Jakarta : EGC, 2011

Depkes RI. 2010. Manajemen Bayi Berat Badan Lahir Rendah (BBLR) untuk Bidan Desa. Jakarta. Depkes RI

Dewi, Vivian Nanny Lia. 2012. Asuhan Kehamilan untuk Kebidanan. Jakarta : Selamba Medika

Fajri, Riska. 2015. Faktor-faktor yang Berhubungan dengan kejadian Berat Badan Lahir Rendah (BBLR) di RSUD dr.Zainoel Abidin Banda Aceh Tahun 2015 (Diunduh 2 November 2018).

Jannah, Nurul. 2012. Asuhan Kebidanan Kehamilan. Ed. I. Yogyakarta. ANDI

Maryunani, Anik, Nurhayati. 2009. Asuhan Kegawatdaruratan dan Penyulit Pada Neonatus. Jakarta. TIM, 2009

Maryanti, Dwi, dkk. 2011. Buku Ajar NeonatusBayidanBalita. Jakarta. TIM, 2011

Manuaba. 2010. Pengantar Kuliah Obstetri. Jakarta. EGC 
Journal of Healthcare Technology and Medicine Vol. 6 No. 2 Oktober 2020

Universitas Ubudiyah Indonesia

e-ISSN : 2615-109X

Oktaviani, E, 2016. Hubungan Usia, Paritas Dan Kehamilan Ganda Dengan Kejadian BBLR di RSUD Abdoel Moeloek Provinsi Lampung (Diunduh 5 Desember 2018)

Pantiawi, Ika.2010. Bayi Dengan Berat Badan Lahir Rendah (BBLR). Yogyakarta: NuhaMedika

Prawirohardjo, Sarwono, 2010. Ilmu Kebidanan. Jakarta. PT. Bina pustaka Sarwono Prawirohardjo

Profil Kesehatan Aceh. 2016. www.dinkes.acehprov.go.id (Diakses Januari 2019)

Profil Kesehatan Kota Banda Aceh. 2017. www.dinkes.kotabandaaceh.go.id (Diunduh 4 Januari 2019)

Rahmalia, Riski. 2017. Faktor-faktor yang Berhubungan dengan Kejadian Berat Badan Lahir Rendah (BBLR) di Puskesmas Singkil Kabupaten Aceh Singkil 2016 (Diunduh 5 Desember 2018)

Rukiah, Ai Yeyeh, dkk. 2010. Asuhan Neonatus Bayi Dan Anak Balita. Jakarta. Trans Info Media

Sasmita, Feni. 2014. Faktor-faktor yang Berhubungan dengan Kejadian Berat Badan Lahir Rendah (BBLR) di RSUD Zainoel Abidin Banda Aceh Tahun 2014 (Diunduh 4 Januari 2019)

Susilowati, E, 2016. Faktor Risiko yang Berhubungan dengan Kejadian Berat Badan Lahir Rendah Pada Neonatus yang Dirawat di RSUP Prof. Dr. R. D. Kandou Periode Januari 2015-Juli 2016 (Diunduh 4 Januari 2019).

WHO. 2015. Departement of Reproductive Health and Research. Managing Newborn Problem: a gufne for Doctors, Nurse and Midwife. WHO library cataluging-in-publication data. Geneva (Diunduh 10 Desember 2018). 